\title{
Reflexiones en torno a las dificultades para acceder a créditos tendientes a adquirir una vivienda
}

Reflections on the difficulties in the acces to loans for acquiring a bome

Reflexões em torno das dificuldades no acesso a empréstimos para adquirir uma casa

Réflexions sur les difficultés d'accès à des prêts pour l'acquisition d'une maison

关于获取房屋贷款困难的思考

Natalia Lorena Barriviera ${ }^{1}$ Universidad Nacional

Valeria Griselda Fiodorov ${ }^{2}$ de La Plata

Revista Derechos en Acción ISSN 2525-1678/ e-ISSN 2525-1686

Año 4/No 12 Invierno 2019 (21 junio a 20 septiembre), 143-158

DOI: https://doi.org/10.24215/25251678e302

ORCID: https://orcid.org/0000-0002-8233-8229

https://orcid.org/0000-0002-5941-6807

Recibido: $17 / 08 / 2019$

Aprobado: 29/08/2019

Resumen: En el presente artículo efectuamos reflexiones críticas sobre el alcance y/o suficiencia de las medidas adoptadas por el gobierno del Presidente Macri destinadas a facilitar el acceso a la primera vivienda familiar, a través de créditos hipotecarios. En momentos de crisis económica provocada por el alto índice de inflación, sueldos que pierden poder adquisitivo, pérdida del empleos, aumento de la pobreza y de la indigencia, caída del consumo y de la producción, incremento de personas en situación de calle, montos irrisorios de los haberes jubilatorios,

\footnotetext{
1 Abogada-Escribana (UNLP). Prof. Adj. Ord. en Derecho Notarial y Registral.

c. e.: barri_natalia@yahoo.com.ar

2 Abogada-Escribana (UNLP). c. e.: valeriagfiodorov@gmail.com
} 
suba del valor del transporte público, quita de subsidios a las tarifas de gas y de luz, cierre de comercios, de pequeñas y medianas empresas, y la estrepitosa variación del valor del dólar que repercute en todo lo señalado, generan situaciones imprevistas que perjudicaron entre otros, a quienes adquirieron créditos hipotecarios en UVA. El perjuicio padecido por estos adquirentes de inmuebles mediante créditos hipotecarios en UVA, se suscitó a partir del incremento del valor de la cuota mensual a abonar, que pasaron a afectar gran porcentaje de sus salarios, duplicando y/o triplicando el valor de las cuotas iniciales. Ello los llevó en algunos casos a refinanciar la deuda con las entidades bancarias, debiendo hoy en día montos mayores a aquellos contraídos al inicio.

Palabras claves: vivienda, crédito hipotecario.

Abstract: In this article we make critical reflections on the scope and / or sufficiency of the measures adopted by the government of President Macri destined to grant access to the first family home, through mortgage loans. In times of economic crisis caused by the high rate of inflation, salaries that lose purchasing power, loss of jobs, increase in poverty and destitution, drop in consumption and production, increase of homeless, derisory amounts of retirement assets, increase in the value of public transport, removal of subsidies to gas and electricity tariffs, closing of businesses, small and medium enterprises, and the resounding variation in the value of the dollar, which has an impact on all that, generate unforeseen situations that harmed, among others, those who acquired mortgage loans at UVA. The damage suffered by these purchasers through mortgage loans in UVA, was caused from the increase in the value of the monthly installment to be paid, which began to affecta large percentage of their salaries, doubling and/ortripling thevalue of the initial installments. This led them in some cases to refinance the debt with the banking entities, owing today greater amounts to those incurred at the beginning.

Keywords: housing, mortgage credit

Resumo: No presente artigo fazemos reflexões críticas sobre 0 alcance e/ou suficiência das medidas adotadas pelo governo do Presidente Macri destinadas a facilitar o acesso à primeira casa familiar, por meio de empréstimos hipotecários. Em tempos de crise econômica causada pela alta taxa de inflação, salários que perdem poder aquisitivo, perda de empregos, aumento da pobreza e da indigência, queda do consumo e da 
produção, aumento de pessoas em situação de rua, quantias irrisórias de ativos de aposentadoria, aumento do valor do transporte público, remoção de subsídios às tarifas de gás e energia elétrica, fechamento de comércios, pequenas e médias empresas, e a variação abrupta no valor do dólar que tem impacto em tudo o que é indicado, gera situações imprevistas que prejudicaram, entre outros, aqueles que adquiriram empréstimos hipotecários em UVA. Os danos sofridos por estes compradores de imóveis mediante empréstimos hipotecários em UVA, foram causados a partir do aumento na cota mensal a ser paga, que começou a afetar uma grande porcentagem de seus salários, dobrando e/ou triplicando o valor das cotas iniciais. Isto levou-os em alguns casos a refinanciar a dívida com as entidades bancárias, devendo hoje maiores quantias àquelas contraídas ao início.

Palavras-chave: casa, crédito hipotecário.

Résumé: Dans cet article, nous faisons des réflexions critiques sur la portée et / ou la suffisance des mesures adoptées par le gouvernement du président Macri, visant à faciliter l'accès à la première maison familiale, a travers de prêts hypothécaires. En cette période de crise économique causée par le taux d'inflation, les salaires portant de pouvoir d'achat, la perte d'emplois, l'augmentation de la pauvreté et du dénuement, la baisse de la consommation et de la production, I'augmentation du nombre de personnes dispossesed, les montants dérisoires des augmentations de la retraite, augmentation de la valeur du transport, suppression des subventions aux tarifs du gaz et de l'électricité, fermeture d'activités, petites et moyennes entreprises, et la variation brusque de la valeur du dollar, qui a une incidence sur tout ce qui est indiqué, situations imprévues qui font mal aux personnes qui ont contracté des emprunts hypothécaires chez UVA ont été genereés. Le préjudice qu'ils ont subi provenait de l'augmentation de la valeur de la mensualité à payer, qui affectait ensuite un pourcentage élevé de leurs salaires, doublant et / ou triplant la valeur des premières échéances. Cela les a amenés dans certains cas à refinancer la dette auprès des entités bancaires, avec montants plus importants que ceux engagés au début.

Mot-clés: logement, crédit hypothécaire.

摘要: 在本文中, 我们对马克里总统政府通过抵押贷款促进进入第 一个家庭住所采取的措施的范围和/或充分性进行了批判性思考。在 高通货膨胀造成的经济危机时期, 失去购买力的工资, 失业, 贫困和 
贫困加剧, 消费和生产下降, 街头人口增加, 嘲弄数额退休资产增加, 公共交通价值增加, 取消对燃气和电费的补贴, 企业关闭, 中小企业 关闭, 以及对所指示的一切产生影响的美元价值的巨大变化, 产生不 可预见的情况,其中包括那些在UVA获得抵押贷款的人。这些房地产 购买者通过UVA抵押贷款遭受的损害是由于每月分期付款的价值 增加造成的,这开始影响他们工资的很大一部分, 使初始分期付款的 价值翻倍和/或增加三倍. 这导致他们在某些情况下为银行实体的债 务再融资,因为今天的债务金额与开始时的金额相当。

关键字: 住房, 抵押贷款.

\section{Introducción}

En la Argentina de hoy, la crisis económica afecta a diversos sectores sociales (especialmente a los a los sectores vulnerables -ancianos; personas con discapacidad), el alto índice de inflación ${ }^{3}$ y la estrepitosa variación del valor del dólar ${ }^{4}$ repercuten en los sueldos que pierden poder adquisitivo ${ }^{5}$, se produce la pérdida del empleos, aumento de la pobreza y de la indigencia, caída del consumo y de la producción, incremento de personas en situación de calle, pago de montos irrisorios de los haberes jubilatorios, suba del valor del transporte público, quita de subsidios a las tarifas de gas y de luz, cierre de comercios, de pequeñas y medianas empresas, entre otras, que impactaron negativamente en el poder adquisitivo de la población, imposibilitando y paralizando el acceso a las viviendas. En este punto, focalizaremos en quienes adquirieron créditos hipotecarios en UVA, fuertemente afectados por la variación de los montos de cuotas mensuales a abonar por los créditos hipotecarios contraídos.

\footnotetext{
3 Según el Instituto Nacional de Estadística y Censos (Indec) vertiginosa inflación del 47\% —la más alta en casi tres décadas — que arrasó con los salarios.

4 El último año duplicó su valor.

5 Según el Indec, una familia tipo (dos adultos y dos niños) necesita más de dos salarios mínimos para no ser pobres.
} 
Si concentramos nuestra atención en la adquisición de bienes o productos, notamos como una vez más en nuestro país, la suba del valor del dólar repercute de manera automática en el incremento de precios de los bienes o productos que consumimos-combustible, alimentos, vestimenta, tarifas de servicios- transformándose en una rueda en continuo avance, que no tiene miras de aletargar su paso y mucho menos de pararlo. Ello impacta asimismo en el valor de los inmuebles, que son cotizados a valor dólar -que alejan de los argentinos y las argentinas (-cuyos sueldos se cobran en Pesos- devaluados a cada segundo), el tan ansiado sueño de comprar su techo propio.

"En la Argentina, el déficit habitacional es uno de los grandes temas postergados que afecta a más del 25\% de los hogares" ${ }^{\text {. }}$ La realidad es que debido a la devaluación quienes adquirieron créditos hipotecarios en UVA están endeudadísimos y muy asustados porque cada vez pagan más de lo que tenían previsto por la modalidad UVA, que se han tornado variables y reajustables ya que van de la mano de la inflación. Por est motivo, muchos deudores hipotecarios temen perder su casa-adquirida con el crédito solicitado- ya que el Banco prestador del crédito, ante la morosidad podría instar el proceso de remate de esos inmuebles.

Ello ha frenado la adquisición de inmuebles para vivienda, y no se vislumbra por parte del gobierno nacional impulso de políticas públicas destinadas al acceso de la vivienda, hasta las medidas anunciadas en abril de 2019 bajo el título de "Medidas Económicas y Sociales" que constan de un paquete de instrumentos con los cuales buscará impulsar el consumo y combatir la recesión, de las cuales nos ocuparemos exclusivamente a las relacionadas con el acceso a la vivienda.

Resulta atinente visualizar los resultados de la Estadística que lleva el Colegio de Escribanos Bonaerense sobre el número de compraventas autorizadas en los períodos 2018/2019. El siguiente cuadro se confeccionó tomando esos datos, que permite advertir

6 PROCREAR (2019). "La solución de la casa propia”. Ministerio del Interior y Obras Públicas. En línea en: https://www.argentina.gob.ar/micasa/quiero-micasa/procrear/quees. 
una abrupta caída en el número de compraventas autorizadas en el período Marzo/2018 respecto al período Marzo/2019.

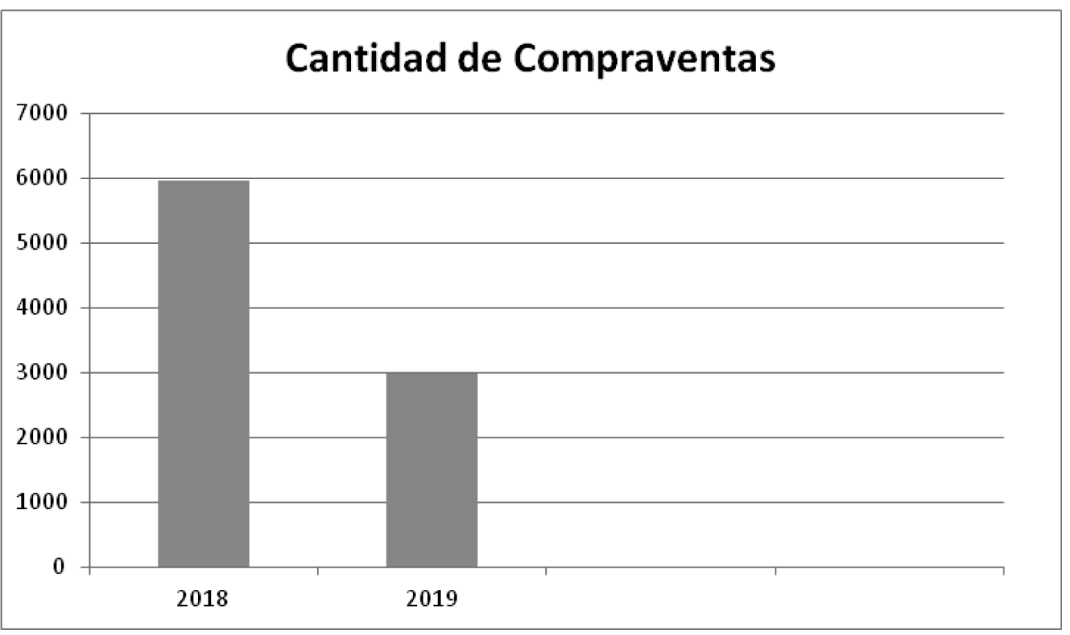

Otra de las estadísticas publicadas por el Colegio de Escribanos Bonaerense, indica la caída en la cantidad de hipotecas, informando dicho Colegio que: “... en marzo se contabilizaron 435 , lo que representó una disminución del 1,6\% con respecto a febrero de este año y una disminución interanual del 91,7\% (5.253 en marzo de 2018). En los montos la disminución fue del $72,7 \%$ (\$2.405.077.744 en marzo de 2019 y \$ 8.799.434.140 en marzo de 2018)."7

\section{Adquisición de viviendas a través de Créditos UVA}

Los créditos en UVAs fueron lanzados en el año 2016 para adquirir inmuebles y automotores. La Unidad de Valor Adquisitivo UVA equivale a la milésima parte del costo promedio de

7 El cuadro con las estadísticas puede consultarse en este sitio web, dentro del menú "El Colegio/ Sala de prensa / Estadísticas". Colegio de Escribanos, Provincia de Buenos Aires (2019). "Se reconocieron las últimas estadísticas del mercado inmobiliario". En línea en: http://www.colescba.org.ar/portal/novedades/noticias/2389-se-conocieron-las-ultimasestadisticas-del-mercado-inmobiliario.html 
construcción de un metro cuadrado de vivienda. El valor se actualiza diariamente en función a la variación del CER (Coeficiente de Estabilización de Referencia), basado en el índice de precios al consumidor. El valor de la UVA en pesos se publica en el Banco Central de la República Argentina. ${ }^{8}$

Muchas personas adquirieron un Crédito UVA, con la idea de dejar de alquilar y con ese dinero invertir en una casa propia. Durante el año 2017 el monto de la cuota de un crédito hipotecario, rondaba el valor de un canon locativo mensual. Ello derivó en la adquisición de viviendas con créditos hipotecarios en UVAs.

En los tiempos que corren, esa situación se alteró, costando menos alquilar un inmueble que abonar la cuota mensual de un préstamo enmarcado en el Crédito Hipotecario UVA adquirido9. La modificación en el valor de las cuotas resultó altamente perjudicial para quienes tomaron esos créditos, "las cuotas de los créditos UVA aumentaron un 18,5\% desde Enero a Mayo de 2019, y en tres años -entre 2016 y 2019-un 147\% en términos nominales ${ }^{10 "}$ de allí se desprende la variación mencionada entre abonar una cuota mensual de un Crédito adquirido en

8 Según Observatorio Económico Social UNR (2018). UVA Unidad en valor adquisitivo. En línea en: http://www.observatorio.unr.edu.ar/unidad-en-valor-adquisitivo-uva/

9 "A mediados de 2017, en pleno auge del sistema UVA, una familia podía lograr que el Banco Nación le preste a 30 años hasta el 80\% del valor de un dos ambientes usado de 43 metros cuadrados en un barrio porteño medio, si mostraba tener ingresos en blanco por $\$ 26.400$ al mes. Ese préstamo tenía una cuota inicial de $\$ 6.750,12 \%$ menor a los $\$ 7.655$ que costaba alquilar un inmueble igual. Actualmente, el valor promedio del alquiler para un departamento de dos ambientes es de $\$ 14.349$, mientras que para un tres ambientes asciende a $\$ 20.088$ por mes. Para pedir el mismo crédito hoy el banco exigirá ganar $\$ 130.000$ al mes, y la cuota arranca en casi \$33.000.". IProfesional Economía (2019). "Las cuotas de los créditos UVA subieron más que los alquileres". En línea en: https://www.iprofesional.com/ economia/289798-inflacion-ingreso-hipotecario-Las-cuotas-de-los-creditos-UVA-subieronmas-que-los-alquileres fecha de consulta 04/06/2019.

10 Casas, Ximena (2019).. "Créditos UVA luego de las crisis: las cinco claves que hay que conocer sobre los cambios en esta modalidad de préstamos hipotecarios". Diario Infobae, Sección Economía:. En línea en: https://www.infobae.com/economia/2019/06/23/ creditos-uva-luego-de-la-crisis-las-cinco-claves-que-hay-que-conocer-sobre-los-cambiosen-esta-modalidad-de-prestamos-hipotecarios/ 
UVA y abonar la mensualidad de un alquiler promedio. Como correlato, los deudores debieron solicitar ante las entidades bancarias la extensión del plazo de las hipotecas.

\section{Créditos hipotecarios en UVA entre 2017 y 2019}

\begin{tabular}{|c|c|c|c|c|c|}
\hline $\begin{array}{c}\text { Tipo } \\
\text { crédito } \\
\text { hipotecario }\end{array}$ & Destino & Requisitos & Monto & Condiciones & Cuota \\
\hline $\begin{array}{l}\text { Ahorro } \\
\text { Joven } \\
\text { Procrear }\end{array}$ & $\begin{array}{l}\text { Vivienda } \\
\text { única }\end{array}$ & $\begin{array}{l}\text { Edad entre } 18 \\
\text { y } 35 \text { años. } \\
\text { Trabajadores } \\
\text { formales o } \\
\text { informales, } \\
\text { monotributistas } \\
\text { con antigüe- } \\
\text { dad de un año. } \\
\text { Ingreso } \\
\text { mensual } \\
\text { entre } \$ 18.000 \\
\text { y } \$ 36.000\end{array}$ & $\begin{array}{l}\text { hasta } 60 \\
\text { mil UVA o } \\
\$ 1.200 .000\end{array}$ & $\begin{array}{l}\text { Debe ahorrar } \\
\text { un } 5 \% \text { del } \\
\text { valor de la } \\
\text { vivienda, hay } \\
\text { que constituir } \\
\text { un plazo } \\
\text { fijo en UVA. } \\
\text { Subsidio del } \\
\text { Estado hasta } \\
\$ 240.000 \text {. }\end{array}$ & $\begin{array}{l}\text { Entre } \$ 6500 \\
\text { y } \$ 5.500 \\
\text { mensuales }\end{array}$ \\
\hline $\begin{array}{l}\text { Crédito } \\
\text { hipotecario } \\
\text { UVA }\end{array}$ & $\begin{array}{l}\text { Para la } \\
\text { construcción } \\
\text { y adqui- } \\
\text { sición de } \\
\text { viviendas. }\end{array}$ & $\begin{array}{l}\text { Cuota ingreso } \\
\text { el } 30 \% \text {. Cuota } \\
\text { a financiar el } \\
70 \%\end{array}$ & $\begin{array}{l}\text { Hasta } \\
\$ 5.000 .000 \\
\text { en bancos } \\
\text { privados } \\
\text { y hasta } \\
\$ 3.000 .000 \\
\text { en públicos }\end{array}$ & $\begin{array}{l}\text { Taza: desde el } \\
3,5 \% \text { al 8,5\% } \\
\text { anual. } \\
\text { El deudor } \\
\text { adeuda el } \\
\text { equivalente en } \\
\text { UVA. }\end{array}$ & $\begin{array}{l}\text { Entre } \$ 5.200 \\
\text { a } \$ 5.600 \\
\text { por cada } \\
\text { un millón } \\
\text { solicitado. } \\
\text { Cuota } \\
\text { variable por } \\
\text { inflación. }\end{array}$ \\
\hline $\begin{array}{l}\text { Construcción } \\
\text { vivienda úni- } \\
\text { ca en terreno } \\
\text { propio }\end{array}$ & $\begin{array}{l}\text { Vivienda } \\
\text { única }\end{array}$ & $\begin{array}{l}\text { Ser titular del } \\
\text { terreno. y }\end{array}$ & $\begin{array}{l}\text { Hasta } \\
\$ 2.770 .000 . \\
\text { No debe } \\
\text { superar el } \\
100 \% \text { del } \\
\text { valor de la } \\
\text { obra. }\end{array}$ & $\begin{array}{l}\text { Disponer de } \\
\text { un ahorro } \\
\text { del } 20 \% \text { del } \\
\text { valor de la } \\
\text { propiedad a } \\
\text { construir. }\end{array}$ & $\begin{array}{l}1^{\circ} \text { tramo } 30 \\
\% \text { del monto } \\
\text { a financiar. } \\
\text { El } 2^{\circ} \text {, es del } \\
50 \% \text { y el } \\
3^{\circ} \text { pago del } \\
20 \% \text {. }\end{array}$ \\
\hline
\end{tabular}




\begin{tabular}{|c|c|c|c|c|c|}
\hline $\begin{array}{l}\text { Segunda } \\
\text { vivienda UVA }\end{array}$ & $\begin{array}{l}\text { Construcción } \\
\text { y adquisición } \\
\text { de vivienda }\end{array}$ & $\begin{array}{l}\text { La cuota } \\
\text { hasta } 30 \% \text { de } \\
\text { los ingresos } \\
\text { familiares. }\end{array}$ & $\begin{array}{l}\$ 5.000 .000 \\
\text { en bancos } \\
\text { privados y } \\
\$ 3.000 .000 \\
\text { en bancos } \\
\text { públicos. }\end{array}$ & $\begin{array}{l}\text { Se finanza el } \\
80 \%\end{array}$ & $\begin{array}{l}\text { Aproximado } \\
\$ 8.000 \text {. }\end{array}$ \\
\hline $\begin{array}{l}\text { Adquirir } \\
\text { vivienda de } \\
\text { pozo }\end{array}$ & $\begin{array}{l}\text { Es para la } \\
\text { adquisición de } \\
\text { un inmueble } \\
\text { de pozo. }\end{array}$ & $\begin{array}{l}\text { El comprador } \\
\text { puede ser una } \\
\text { constructora } \\
\text { o un usuario } \\
\text { final Se } \\
\text { financia hasta } \\
70 \%\end{array}$ & $\begin{array}{l}\text { Hasta } \\
\$ 3.500 .000\end{array}$ & $\begin{array}{l}\text { Para el usua- } \\
\text { rio final tiene } \\
\text { una tasa del } \\
6,9 \% \text {, se } \\
\text { ajusta el } \\
\text { UVA o CER, } \\
\text { actualizables } \\
\text { por el índice } \\
\text { de la cons- } \\
\text { trucción. }\end{array}$ & $\begin{array}{l}\text { Los } \\
\text { desembolsos } \\
\text { son según los } \\
\text { avance de la } \\
\text { obra. }\end{array}$ \\
\hline $\begin{array}{l}\text { Crédito Puente } \\
\text { en UVA. }\end{array}$ & Inmuebles & $\begin{array}{l}\text { Es para } \\
\text { quienes son } \\
\text { dueños y quie- } \\
\text { ren comprar } \\
\text { un inmueble } \\
\text { antes de } \\
\text { vender el que } \\
\text { ya tienen. }\end{array}$ & $\begin{array}{l}\text { Hasta } \\
\$ 2.770 .000 \text {. }\end{array}$ & $\begin{array}{l}\text { Se empieza } \\
\text { a pagar a } \\
\text { partir de los } \\
30 \text { días de } \\
\text { la compra. } \\
\text { La hipoteca } \\
\text { a un plazo } \\
\text { máximo de } \\
30 \text { años. }\end{array}$ & $\begin{array}{l}\text { Cuota } \\
\text { mensual. La } \\
\text { financiación } \\
\text { es por UVA. } \\
\text { Hasta el 75\% } \\
\text { de la vivienda } \\
\text { a comprar. }\end{array}$ \\
\hline $\begin{array}{l}\text { Tasa fija los } \\
\text { primeros } 3 \\
\text { años }\end{array}$ & $\begin{array}{l}\text { Para la } \\
\text { adquisición, } \\
\text { cambio, } \\
\text { ampliación, } \\
\text { refacción o } \\
\text { terminación } \\
\text { de vivienda. }\end{array}$ & & $\begin{array}{l}\text { Hasta } \\
\$ 2.770 .000 \text {. }\end{array}$ & $\begin{array}{l}\text { La tasa es } \\
\text { fija por } 36 \\
\text { meses. En el } \\
\text { mes 37, la } \\
\text { tasa varía. }\end{array}$ & $\begin{array}{l}\text { Cuota con } \\
\text { tasa fija por } \\
3 \text { años, en } \\
\text { el cuarto } \\
\text { aumenta pero } \\
\text { no podrá ser } \\
\text { superior a la } \\
\text { suba de los } \\
\text { salarios. }\end{array}$ \\
\hline $\begin{array}{l}\text { Crédito Hipote- } \\
\text { cario Tasa Fija } \\
\text { para compra } \\
\text { de primera o } \\
\text { segunda vi- } \\
\text { vienda }\end{array}$ & $\begin{array}{l}\text { El préstamo } \\
\text { es para cubrir } \\
\text { hasta el } 70 \% \\
\text { de la primera } \\
\text { vivienda y el } \\
60 \% \text { en el } \\
\text { caso de la } \\
\text { segunda }\end{array}$ & & $\begin{array}{l}\text { Hasta } \\
\$ 3.600 .000 \text {. }\end{array}$ & $\begin{array}{l}\text { El cliente } \\
\text { podrá tener } \\
\text { un préstamo } \\
\text { a } 10 \text { años } \\
\text { con una tasa } \\
\text { fija de 18\% } \\
\text { TNA. }\end{array}$ & $\begin{array}{l}\text { La primera } \\
\text { mitad es a } \\
\text { interés fijo y } \\
\text { luego Badlar } \\
\text { más } 4 \% \text {. }\end{array}$ \\
\hline
\end{tabular}




\begin{tabular}{|c|c|c|c|c|c|}
\hline $\begin{array}{l}\text { Para } \\
\text { construcción y } \\
\text { adquisición de } \\
\text { vivienda }\end{array}$ & $\begin{array}{l}\text { Es para vi- } \\
\text { vienda única, } \\
\text { familiar y de } \\
\text { ocupación } \\
\text { permanente. }\end{array}$ & $\begin{array}{l}\text { Personas } \\
\text { Humanas entre } \\
18 \text { y } 55 \text { años, } \\
\text { y familias } \\
\text { que tengan } \\
\text { ingresos entre } \\
2 \text { a } 4 \text { salarios } \\
\text { mínimos, } \\
\text { vitales y } \\
\text { móviles. }\end{array}$ & $\begin{array}{l}\text { Hasta } \\
\$ 1.650 .000 .\end{array}$ & $\begin{array}{l}\text { Hay quienes } \\
\text { recibieron } \\
\text { el subsidio } \\
\text { del Estado } \\
\text { pero aun no } \\
\text { pudieron } \\
\text { comprar la } \\
\text { vivienda. }\end{array}$ & $\begin{array}{l}\text { Cuota de } \\
\$ 3.040 \text { men- } \\
\text { suales aprox, } \\
\text { dependiendo } \\
\text { del monto } \\
\text { solicitado. }\end{array}$ \\
\hline
\end{tabular}

**Tienen en común plazos de 20 años a 30 años.

\section{Paquetes de medidas para reactivar la economía y contener la inflación}

Para paliar la crisis económica señalada, el Presidente Mauricio Macri anunció en abril del año 2019 un paquete de "Medidas Económicas y Sociales"11, buscando mediante la reactivación de

11 1. Precios y consumo/Acuerdo de precios de productos esenciales: Para mantener el precio durante seis meses de 60 productos de la canasta básica se realizó un acuerdo con 16 empresas de primera línea. Las empresas se comprometen a que haya disponibilidad de esos productos./ Beneficios y Créditos ANSES: Para los beneficiarios de ANSES con su tarjeta de débito tendrán una red de descuentos de entre el $10 \%$ y el $25 \%$ en supermercados, negocios de ropa, iluminación, viajes y turismo, electrodomésticos, línea blanca y materiales para la construcción. Se amplían los Créditos de Anses./ Ley de Lealtad Comercial: El Gobierno va a decretar un "Régimen de Lealtad Comercial", con el fin de evitar monopolios o dominios de empresas líderes. Secretaría de Comercio Interior tendrá la atribución de sancionar "conductas desleales o anticompetitivas", para a los más débiles./ Cortes de carne a precios accesibles: Los grandes frigoríficos van a "vender 120.000 kilos por semana de asado, vacío y matambre a $\$ 149$ el kilo (precio final) en la feria minorista del Mercado Central y en las bocas de expendio de cada uno de los frigoríficos". 2. Tarifas de servicios públicos/ Electricidad, gas y transporte: En lo que resta del año no aumentaran las tarifas de electricidad, gas y transporte público./ Telefonía celular. Se va a "mantener el precio de la telefonía celular de las líneas prepagas durante cinco meses" 3. Apoyo para las pyme/ Plan de pagos de AFIP: Es regularizar deudas tributarias vencidas de todos los contribuyentes, con una tasa menor a las de planes previos y hasta 60 cuotas./ Mejores condiciones para comercios: a partir de ahora aquellos comercios que cobran con tarjetas de créditos, a los 10 días de efectuada la operación tendrán su dinero./ Menos retenciones para pymes exportadoras. 4. Beneficios sociales/ Descuentos de hasta el 70\% en medicamentos para AUH/ Créditos para conexiones de gas, será un crédito de 60 cuota y tasa baja. Valor desde \$489./En Presidencia de la Nación (2019). Medidas Económicas y Sociales. En línea en: https://www.casarosada.gob.ar/pdf/ Medidas\%20econmicas\%20y\%20sociales.pdf 
la economía, incrementar el consenso social perdido, y alentar a inversionistas a apostar por nuestro país. Este paquete de medidas se encontrará vigente hasta octubre de 2019 ( seis meses).

Dentro del punto cuarto cuyas medidas se encuentran destinadas al beneficio social, el gobierno dispuso abrir un nuevo llamado al Procrear. En esta oportunidad estableció que diez mil (10.000) nuevas familias puedan acceder a su vivienda. Las familias aportarán un 10\% del valor de la vivienda y el Estado Nacional el $20 \%$, con un subsidio no reembolsable -el promedio de este subsidio será de \$550.000- según información extraída de la página web de Casa Rosada ${ }^{12}$.

Otra de las medidas es ofrecer para créditos de hasta 140.000 UVAs, seguros optativos contra saltos de la inflación, por el $1,5 \%$ de la cuota.

\section{Alcance de las medidas de gobierno relacionadas con el Procrear ${ }^{13}$}

Irrisoriamente, dentro del nuevo llamado del Procrear el gobierno prevé otorgar 10.000 créditos para acceder a la primera vivienda familiar, con esta política pretende mitigar la problemática habitacional en todo el territorio de la República Argentina.

Reflexionemos, Argentina tiene una extensión territorial de aproximadamente $2780400 \mathrm{~km}^{2}$, con una población aproximada a 45.376.763 de argentinos y argentinas, con una crisis habitacional, donde ya en el 2018 "uno de cada tres hogares tiene problemas de vivienda, (...) serían unos cuatro millones, de los cuales 1,5 millones son la cantidad de viviendas que

\footnotetext{
12 ídem

13 Mediante el Decreto Nacional N 902/2012 se creó el plan PRO.CRE.AR. BICENTENARIO, Programa de Crédito Argentino del Bicentenario para la Vivienda Única Familiar", con la finalidad de impulsar la actividad económica a través del incentivo a la construcción de viviendas, generando efectos beneficiosos sobre el conjunto de la economía, tanto en la producción, como en el trabajo y el consumo interno.
} 
se necesitan construir" ${ }^{14}$. Sin referirnos a las personas que ni siquiera con crédito pueden acceder a una vivienda, tomando como ejemplo una sola provincia como es Salta, en ella "representa el $44 \%$ del déficit habitacional"15, sumado a ello, el "60\% de población" 16 no puede acceder a un Plan Procrear. A pesar de esta crisis habitacional, el actual Gobierno anunció para el Procrear un llamado para solamente unas $\mathbf{1 0 . 0 0 0}$ familias en toda la Argentina, una medida claramente insuficiente para los valores que venimos mencionando.

Entre los requisitos previstos para ingresar a este Plan Nuevo Procrear se debe contar con un ahorro del 10\% del valor de la propiedad que se pretende adquirir y un $20 \%$ resulta subsidiado por el Estado. Por el 70\% restante del valor del inmueble, se otorga un crédito UVA indexado por inflación más un $7,5 \%$ anual. El valor mensual de las cuotas a abonar por dicho préstamo, ronda aproximadamente la suma de pesos trece mil quinientos (\$13.500) por mes. El plazo es por 30 años. Además los beneficiarios van a pagar un Seguro UVA que "Compensará la diferencia de cuota si el índice de inflación supera al índice salarial en más del 10 por ciento"17. Ejemplo: "Si la inflación acumulada desde el inicio del crédito es del 40 por ciento y el índice salarial creció un 25 por ciento, el seguro cubrirá el 5 por ciento excedente" ${ }^{18}$.

\footnotetext{
14 Cabot Diego (2018). "Crisis habitacional: uno de cada tres hogares tiene problemas de vivienda". Sección Política. Diario La Nación. En línea en: https://www.lanacion.com.ar/politica/crisis-habitacional-uno-de-cada-tres-hogares-tiene-problemas-de-vivienda-nid2121533 15 Corbalán Javier (Sin fecha). "La provincia de Salta tiene un déficit habitacional de más de 72.000 viviendas". Diario El Tribuno. En línea en: https://www.eltribuno.com/ salta/nota/2019-3-31-0-0-0-la-provincia-de-salta-tiene-un-deficit-habitacional-de-mas-de72-000-viviendas/amp

16 Ídem.

17 Diario La Voz. "Las Nuevas líneas de crédito que anunció Nación”. Sección Política./ Créditos. En línea en: https://www.lavoz.com.ar/politica/nuevas-lineas-de-credito-queanuncio-nacion

18 Ídem.
} 


\section{Nuevo llamado Procrear 2019}

\begin{tabular}{|c|c|c|c|c|c|}
\hline $\begin{array}{l}\text { Tipo crédito } \\
\text { hipotecario }\end{array}$ & Destino & Requisitos & Monto & Condiciones & Cuota \\
\hline $\begin{array}{l}\text { NUEVO } \\
\text { LLAMADO } \\
\text { PROCREAR }\end{array}$ & $\begin{array}{l}\text { Vivienda } \\
\text { Solo } 10000 \\
\text { crédito para } \\
\text { todo el país }\end{array}$ & $\begin{array}{l}\text { Debes contar } \\
\text { con un ahorro } \\
\text { del } 10 \% \text { del } \\
\text { valor de la } \\
\text { vivienda. } \\
\text { Se paga un } \\
\text { seguro. }\end{array}$ & $\begin{array}{l}\$ 550.000 . \\
\text { Plazo de } \\
\text { cancelación } \\
30 \text { años }\end{array}$ & $\begin{array}{l}\text { El Estado da un } \\
\text { subsidio del } 20 \% \\
\text { del valor de la } \\
\text { vivienda. } \\
\text { Resto del } \\
\text { valor crédito UVA } \\
\text { indexados por } \\
\text { inflación más un } \\
7,5 \% \text { anual }\end{array}$ & $\begin{array}{l}\text { Aprox. de } \\
\$ 13.500 \\
\text { mensuales }\end{array}$ \\
\hline
\end{tabular}

\section{Situación de los deudores de Creditos UVAs en Provincia de Buenos Aires}

Frente a la difícil realidad que les toca enfrentar a los deudores de créditos en UVAs en la provincia de Buenos Aires, fue presentado ante el Congreso Provincial Bonaerense un proyecto de "LEY DE PROTECCIÓN DE CRÉDITOS HIPOTECARIOS Y PRENDARIOS EN UNIDADES DE VALOR ADQUISITIVOS (UVA) DESTINADOS A LA ADQUISICIÓN DE VIVIENDAS FAMILIARES Y/O AUTOMOTORES OTORGADOS POR EL BANCO PROVINCIA DE BUENOS AIRES" presentado para paliar la crisis que viven aquellos que adquirieron créditos en $\mathrm{UVA}^{19}$.. El objeto del proyecto es dotar al Banco de la Provincia de facultades para proteger a las familias bonaerenses que han adquirido créditos hipotecarios en Unidades de Valor Adquisitivo actualizables por Coeficiente de Estabilización de Referencia "CER" - Ley 25.827 ("UVA") destinados a la adquisición de viviendas familiares. Establece un tope legal de 30\% para le relación entre el salario

19 El autor del proyecto es el senador de UC-FpV Federico Susbielles, quien expresó a la prensa al finalizar la sesión: "No hay argumentos técnicos, financieros ni mucho menos políticos para rechazar esta ley que fue trabajada con las familias deudoras, y que contempla un amplio abanico de posibilidades para evitar el colapso del sistema crediticio". I Según Caballero Manuel (2019). “Escándalo: Cambiemos rechazó la emergencia para tenedores de créditos UVA". Diario InfoBaires24. Sección Sociedad. En línea en: https://www.infobaires24. com.ar/escandalo-cambiemos-rechazo-la-emergencia-para-tenedores-de-creditos-uva/ 
y las cuotas a abonar, evitando que en el futuro se fijen proporciones de peso del crédito superiores a lo razonable. Asimismo, se establece el seguro de cambio para garantizar la efectiva realización de las operaciones independientemente de los vaivenes del tipo de cambio.

Cuadra mencionar que ese proyecto fue rechazado por el bloque oficialista ${ }^{20}$.

\section{Conclusión}

Con el transcurso del tiempo y el paso de diferentes Gestiones Presidenciales, el acceso a créditos tendientes a adquirir viviendas familiares, fue variando.

La descontrolada situación económica y financiera de nuestro país desde 2016 a la fecha, impactó fuertemente en el acceso a la vivienda. Las altas tasas de interés, el incremento del valor de los inmuebles, la suba de dólar, la recesión, la actualización de los créditos por Unidad de Valor Adquisitivo (UVA), perjudicó el bolsillo de quienes, en estos últimos años y a través de políticas públicas erradas, entraron al Programa con el sueño de adquirir su primera vivienda.

Durante la puesta en vigencia del Programa Procrear hasta el año 2015, la variación de las tasas fue mínima, permitiendo que muchos argentinos y argentinas lograran obtener sus viviendas.

Las modificaciones incorporadas por el gobierno actual al Programa Procrear, como medidas económicas y sociales destinadas a incrementar el acceso a la vivienda digna fue la actualización mediante "Unidad de Valor Adquisitivo (UVA)". Los altos niveles de inflación repercutieron en la tasa de interés UVA ocasionando una suba en la cuota del crédito hipotecario, ello trajo a colación que los deudores no paguen las cuotas de

20 La votación contó con 29 votos de Cambiemos, contra 13 votos de la oposición, entre Unidad Ciudadana y el PJ-Unidad y Renovación. El Frente Renovador estuvo ausente." Según Op. Cit. Caballero Manuel (2019. 
los mencionados créditos obtenidos. Ante la falta de pago, los bancos ofrecen a los deudores la refinanciación de sus créditos, actualizando los montos adeudados, por ende los deudores luego de haber abonado una importante cantidad de cuotas, encuentraron que su deuda lejos de disminuir, se abultó. Aparece junto con este malestar y stress, el temible fantasma de perder la única vivienda frente a posibles ejecuciones hipotecarias. Esta situación atenta contra los deudores hipotecarios, que ven totalmente desmejorada su posición y a punto de perder la ilusión de ver crecer a sus hijos e hijas en el seno familiar.

Con las medidas ofrecidas y el llamado a nuevos créditos Procrear cuyo número es insuficiente, la crisis habitacional lejos está de disminuir. Los 10.000 créditos ofrecidos para familias a lo largo y a lo ancho de nuestro territorio Argentino, es una ínfima cantidad que se torna burlona del destino familiar.

Con carácter urgente se necesitan nuevas medidas y políticas públicas destinadas por un lado a aquellos que pueden acceder a un crédito hipotecario con mejoras en la accesibilidad y con tasas más favorables; y por otro lado medidas o planes para que quienes no tienen los ingresos mínimos requeridos, puedan acceder a sus viviendas a través de Procrear u otros programas creados al efecto.

Finalmente, es primordial que todos y todas alcancemos el derecho constitucional de acceso a una vivienda digna, resultando imprescindible que el Estado se involucre activamente en ello mediante nuevas políticas públicas, tendientes a facilitar el acceso al techo propio, ya que citando a Mario Benedetti: "La vivienda no es sólo un bien inmobiliario, es también una forma de consolidación espiritual".

\section{Bibliografía}

Caballero Manuel (2019). "Escándalo: Cambiemos rechazó la emergencia para tenedores de créditos UVA". Diario InfoBaires24. Sección Sociedad. En línea en: https://www.infobaires24.com. ar/escandalo-cambiemos-rechazo-la-emergencia-para-tenedores-de-creditos-uva/ 
Cabot Diego (2018). "Crisis habitacional: uno de cada tres hogares tiene problemas de vivienda". Sección Política. Diario $L a$ Nación. En línea en: https://www.lanacion.com.ar/politica/ crisis-habitacional-uno-de-cada-tres-hogares-tiene-problemasde-vivienda-nid2121533

Casas, Ximena (2019). "Créditos UVA luego de las crisis: las cinco claves que hay que conocer sobre los cambios en esta modalidad de préstamos hipotecarios". Diario Infobae, Sección Economía:. En línea en: https://www.infobae.com/economia/2019/06/23/ creditos-uva-luego-de-la-crisis-las-cinco-claves-que-hay-queconocer-sobre-los-cambios-en-esta-modalidad-de-prestamoshipotecarios/

Colegio de Escribanos, Provincia de Buenos Aires (2019). "Se reconocieron las últimas estadísticas del mercado inmobiliario". En línea en: http://www.colescba.org.ar/portal/novedades/ noticias/2389-se-conocieron-las-ultimas-estadisticas-delmercado-inmobiliario.html Corbalán Javier (2019). "La provincia de Salta tiene un déficit habitacional de más de 72.000 viviendas". Diario El Tribuno. En línea en: https://www.eltribuno. $\mathrm{com} / \mathrm{salta} / \mathrm{nota} / 2019-3-31-0-0-0-$ la-provincia-de-salta-tiene-undeficit-habitacional-de-mas-de-72-000-viviendas/amp

Diario La Voz (2019). "Las Nuevas líneas de crédito que anunció Nación”. Sección Política/ Créditos. En línea en: https://www.lavoz. com.ar/politica/nuevas-lineas-de-credito-que-anuncio-nacion

Jara, Luciano (2018). "UVA Unidad en valor adquisitivo" Observatorio Económico Social Universidad Nacional de Rosario. En línea en: http://www.observatorio.unr.edu.ar/unidad-en-valoradquisitivo-uva/

Presidencia de la Nación (2019). Medidas Económicas y Sociales. En línea en: https://www.casarosada.gob.ar/pdf/Medidas\%20 econmicas $\% 20 \mathrm{y} \% 20$ sociales.pdf

PROCREAR (2019). "La solución de la casa propia". Ministerio del Interior y Obras Públicas. En línea en: https://www.argentina. gob.ar/micasa/quiero-micasa/procrear/quees

IProfesional Economía (2019). "Las cuotas de los créditos UVA subieron más que los alquileres". En línea en: https://www.iprofesional.com/economia/289798-inflacion-ingreso-hipotecarioLas-cuotas-de-los-creditos-UVA-subieron-mas-que-los-alquileres. 